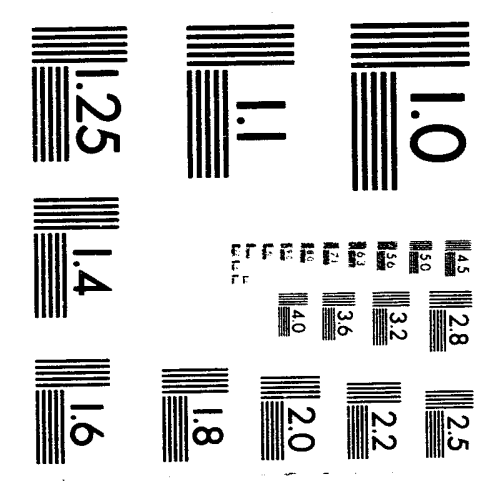



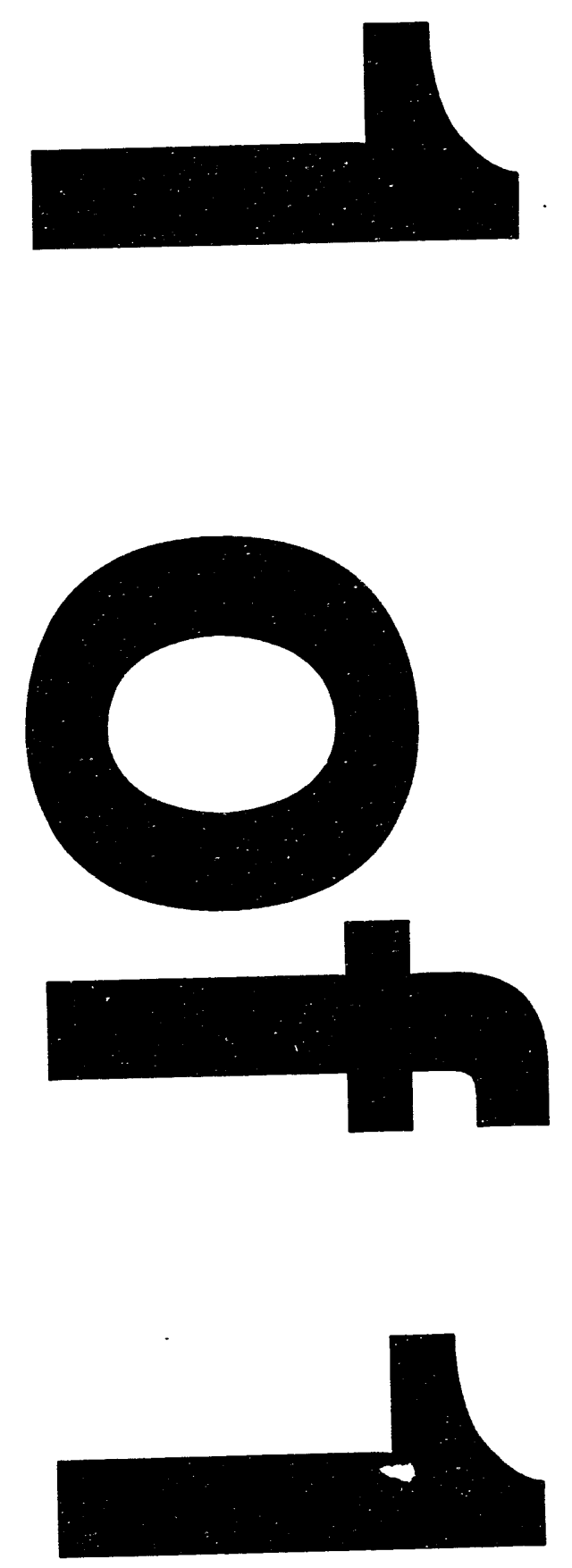
PNL-9439

UC-510

\section{Impact of Access Port Diameter on the Long Reach Manipulator Design}

R. S. Stoughton

April 1994

Prepared for

the U.S. Department of Energy under Contract DE-AC06-76RLO 1830

Pacific Northwest Laboratory

Richland, Washington 99352 


\title{
Impact of Access Port Diameter on the Long Reach Manipulator Design
}

\author{
R. S. Stoughton \\ Pacific Northwest Laboratory \\ Operated by Battelle Memorial Institute
}

\section{Introduction}

Many of the single shell storage tanks (SSTs) on the Hanford site appear to have central 42-in. risers which could be used as access ports for the LRM. However, about half of the tanks are known to not have a central 42-in. riser (Alstad 1991), and it has recently been discovered that of the tanks whose drawings indicate central 42-in. risers, the majority have been plugged, sealed, or taper down to a much smaller diameter at ground level. Thus, it can be assumed that a central access port for the LRM will have to be made. There are many issues involved in determining the best diameter for this access port such as radiation exposure, contamination prevention, and availability of remote excavation technology. This report analyzes the relationship between the access port diameter and the performance characteristics of the LRM. Previous work has assumed that the mast diameter would be $80 \%$ of the access port diameter (Kwon et al. 1993). In this report, the maximum mast diameter will be varied rather than the access port diameter, leaving the issue of the required clearance between the mast and the access port open.

\section{Summary}

A finite element model (FEM) was developed to model the mast, arm, actuators, short reach manipulator (SRM), and end effector(s) when fully extended in an SST (Figure 1). The model consisted of three-dimensional beam elements and mass elements. Space was left for the addition of spring and spring/damper elements for future modeling of joint compliance and closed-loop control actions. The mast was assumed to telescope in three parts, and the arm was modeled as three sequential beams, with a fourth beam element added to the end of the arm to model the SRM.

The FEM analysis was used as input to an optimization routine which varied the diameters and thicknesses of the arm sections in order to maximize the lowest system 
natural frequency. The optimization was performed for a range of payloads from 250 to 1500 pounds and a range of mast diameters from 28 to 64 inches.

The lowest natural frequeincy of the system was found to increase roughly linearly with the mast (or access port) diameter. Increasing the payload from 250 pounds to 1500 pounds with a given mast diameter decreases the natural frequency by roughly 1 $\mathrm{Hz}$. The range of frequencies achievable (without considering joint compliance) varies from about $1 \mathrm{~Hz}$ for a 28 -in. mast with a $1500 \mathrm{lb}$ payload to about $5 \mathrm{~Hz}$ for a 64-in. mast with a $250 \mathrm{lb}$ payload. For large mast diameters ( $>$ about $50 \mathrm{in}$.), the static deflections are very small ( $>1 \mathrm{in}$.) and the stresses on the mast and arm are very low, but the total weight is rather high $(>35000 \mathrm{lbm})$. This indicates that a honeycomb-iike structure could be used to greatly reduce the total system weight without compromising strength. This type of structure could also increase passive damping.

\section{Implementation Details and Justification}

The FEM consisted primarily of three-dimensional beam elements, with mass elements added to model the actuators, SRM, and end effector masses. Space was allowed for the addition of spring and spring/damper elements at the joints which can be used to model joint compliance and closed loop control actions. The mast was assumed to telescope in three parts. ORNL studies have shown that a one piece, non-telescoping mast would require an excessively high tower (Kwon et al. 1993). A total mast height of 50 feet was used, broken down into constant, circular cross section beams of 20,17 , and 13 feet. The mast thickness was assumed to be $1 / 50$ of the mast diameter to satisfy buckling constraints while minimizing the weight of the mast. The diameter of the second mast section was set to be 0.96 times the diameter of the initial section, and the diameter of the third mast section was set to be 0.92 times that of the initial section. A bearing support was assumed 5 feet from the top of the mast. A point mass of $100 \mathrm{lbm}$ was added at the top of the mast to model the moving portion of the mast rotation actuator. A point mass of $200 \mathrm{lbm}$ was added at the bottom of the mast to model the elbow actuator.

The arm extending from the bottom of the mast was modeled as three beams, each of constant circular cross section and 11 feet in length. Point masses of $120 \mathrm{lbm}$ and $80 \mathrm{lbm}$ were placed between the first and second arm sections and the second and third arm sections, respectively, to model the actuators. These actuator masses are likely too small. Subsequent analysis using optimized arm parameters for a $1000 \mathrm{lb}$ load and a 48-in. mast suggested actuator weights of $600 \mathrm{lbm}$ for the elbow, and 300 and $140 \mathrm{lbm}$ for the two arm actuators. The differences in actuator masses are quite small compared to the masses of the arm sections, and should not greatly affect the results presented here. 
The SRM was modeled as a constant circular cross section beam 5 feet in length extending horizontally from the end of the third section of the LRM. The actual length of the SRM will more likely be about 10 feet. The 5-foot length models a 10 foot long SRM inclined $60^{\circ}$ from the horizontal, and places the end effector 38 horizontal feet (roughly the tank radius) from the mast centerline. The total mass of the SRM was assumed to be equal to that of the end effector. Half of this mass was associated with a point mass located at the end of the third section of the LRM. The diameter of the SRM was determined so that the mass of the beam modeling the SRM would be half that of the end effector. The thickness of the beam modeling the SRM was assumed to be one fourth the diameter.

The beam element size was set to 6 inches, resulting in 176 3-D beam elements.

The diameters and thicknesses of the three sections of the LRM were used as design variables for optimization. It was required that the diameters of the arm sections be less than the mast diameter, and that they step down sequentially (i.e., the first section's diameter is greater than the second section's which is greater than the third section's). The objective function to be maximized was the lowest natural frequency of the system. The lowest natural frequency imposes an upper bound on the closed loop bandwidth of the system (Book et al. 1975). Also, since for a single degree-of-freedom

system the natural frequency $\left(\varpi_{n}\right)$ is given by $\sqrt{\mathrm{k} / \mathrm{m}}$ maximizing $\varpi_{\mathrm{n}}$ has the effect of simultaneously maximizing the stiffness while minimizing the weight. The optimization was run for nine different mast diameters $(28,32,26,40,44,48,52,56$, and 64 inches) and seven different end effector loads $(250,400,600,800,1000,1250$, and $1500 \mathrm{lb})$ for a total of 63 runs. It is unlikely that serious consideration will be given to mast diameters in excess of 64 inches. Current estimates of end effector loads are on the order of 250$1000 \mathrm{lbs}$, including operating loads.

\section{Discussion}

The results of the optimization runs are presented graphically in Figures 2-5. Note that the values given for natural frequencies and static deflections are optimistic because compliance in the joints has not yet been considered. For industrial robots, a good "rule of thumb" is to assume than joint compliance and link deflections contribute equally. Tip deflections will increase with the square of the link lengths due to joint compliance, and with the cube of the link lengths due to link deflections. Therefore, it is likely that link deflections will be more significant that joint compliance for the LRM. However, if it is assumed that joint compliance and link deflections contribute roughly equally to the overall stiffness, then static deflections can be expected to be roughly double those of Figure 3, and natural frequencies can be expected to be about 0.7 times those of Figure 2. Note that the mast flexibility is dominant in determining the lowest 
natural frequency. In a test model in which the mast was eliminated, the lowest natural frequency was increased by a factor of about 4 .

There is an approximately linear relationship between the mast diameter and the lowest natural frequency. Figure 2 indicates that a natural frequency of $3 \mathrm{~Hz}$ can be achieved with a mast diameter of 50 inches and a payload of $1000 \mathrm{lbs}$. This likely corresponds to a little over $2 \mathrm{~Hz}$ when joint compliance is considered.

With mast diameters greater than about 42 inches, the static deflection of the tip falls below 2 inches, even for a $1500 \mathrm{lb}$ payload. When the mast diameter exceeds about 55 inches, the static deflection drops to less than $1 / 2$ inch, and doesn't vary much with payload.

The total weight of the manipulator goes up roughly with the square of the mast diameter. This is because most of the total weight is in the mast, and since the minimum thickness of the mast must be 1/50 of the diameter, the mast weight goes up with the square of the diameter. Note that the maximum stress on the mast (given by Mc/I) decreases with the cube of the diameter. Since the stresses are very low with large mast diameters, the buckling constraint in the thickness could likely be relaxed somewhat. A better solution, however, would be to make the mast using a honeycomb-like structure rather than solid material. This would allow the buckling constraint $c_{\text {. }}$ the thickness to be satisfied, the high stiffness to be maintained, the natural frequency to be increased (due to decreased mass), and the weight to be drastically reduced (a factor of four reduction is conceivable). This type of layered structure could also be applied to the arm sections, where the resulting increase in the natural frequency would be more pronounced.

An issue worthy of discussion is the spacing of the natural frequencies of the system. Table 1 presents the first 15 natural frequencies for a representative optimized design. There are typically four frequencies of interest -- two frequencies near the value indicated in the data and two at about twice the indicated value. The lowest mode of vibration tends to be motion of the arm in a horizontal plane with primarily torsional motion of the mast (some mast bending also). The second mode (very close to the first) is essentially in a vertical plane and involves in-phase bending of the arm and mast.

An interesting result of the optimization is that when considering only the lowest natural frequency, the tendency is to drive the system to a configuration with two approximately equal fundamental frequencies. It is not clear what the ranifications of closely spaced frequencies would be. With complex space structures, some active vibration damping algorithms do not perform well with clumped natural frequencies. Clumped natural frequencies can lead to model coupling in which vibrations in one mode will excite one or more other modes. The implicit assumption of linearity in the FEM precludes any analysis of modal coupling. 
The FEM has been developed so that more detailed information can readily be incorporated in the future. For example, the joints have been input as two coincident nodes so that additional elements which model joint flexibility and the closed loop controller can be easily added. These additions will allow for accurate prediction of the closed loop natural frequencies and behavior of the system under various control laws. Different cross sectional shapes can also be incorporated and used as design variables for optimization.

\section{References}

Alstad, A. T. 1991. "Riser Configuration Document for Single-Shell Waste Tanks," WHC-SD-RE-TI-053 Rev. 8, Westinghouse Hanford Company, Richland, Washington.

Book, W. J., et al. 1975. "Feedback Control of Two Beam, Two Joint Systems with Distributed Flexibility," ASME Joumal of Dynamic Systems, Measurement and Control, pp. 424-431.

Kwon, D. S., et al. 1993. "Parametric Design Studies of Long Reach Manipulators," Proc. ANS Topical on Robotics and Remote Systems, Knoxville, TN, Vol. 1, pp. 265-273. 


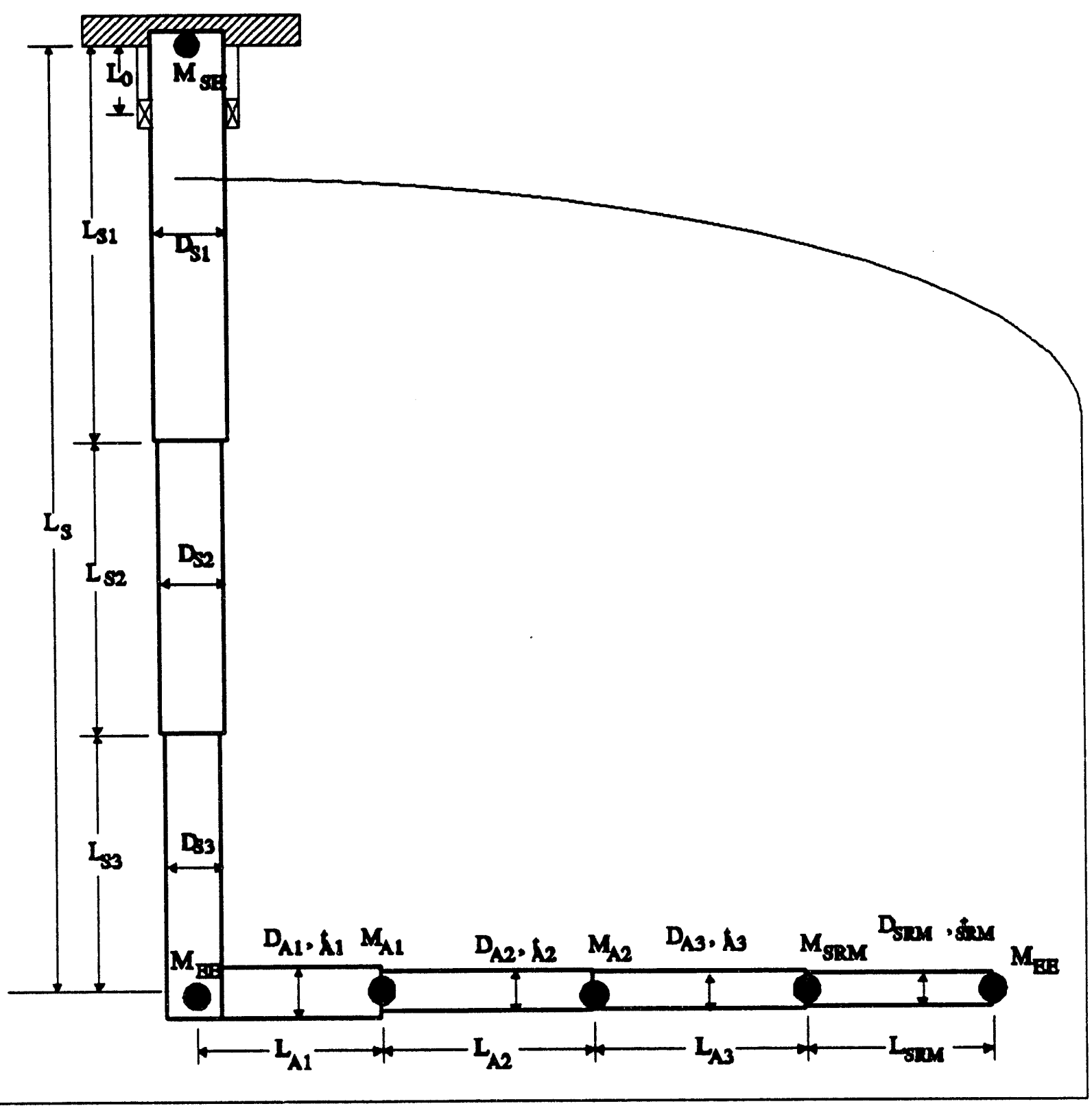

Figure 1 - FEM Model of LRM 


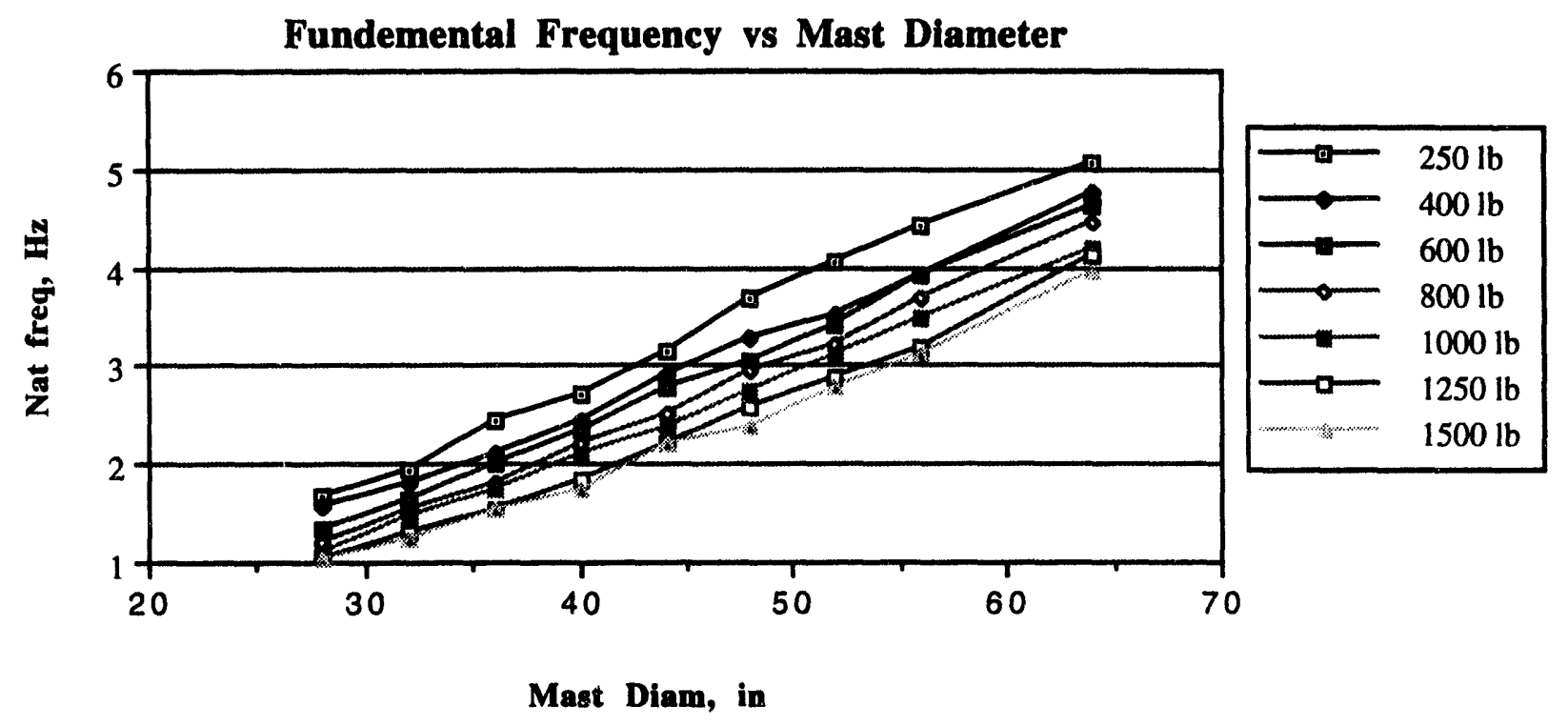

Figure 2 - Relationship between Mast Diameter and Lowest Natural Frequency

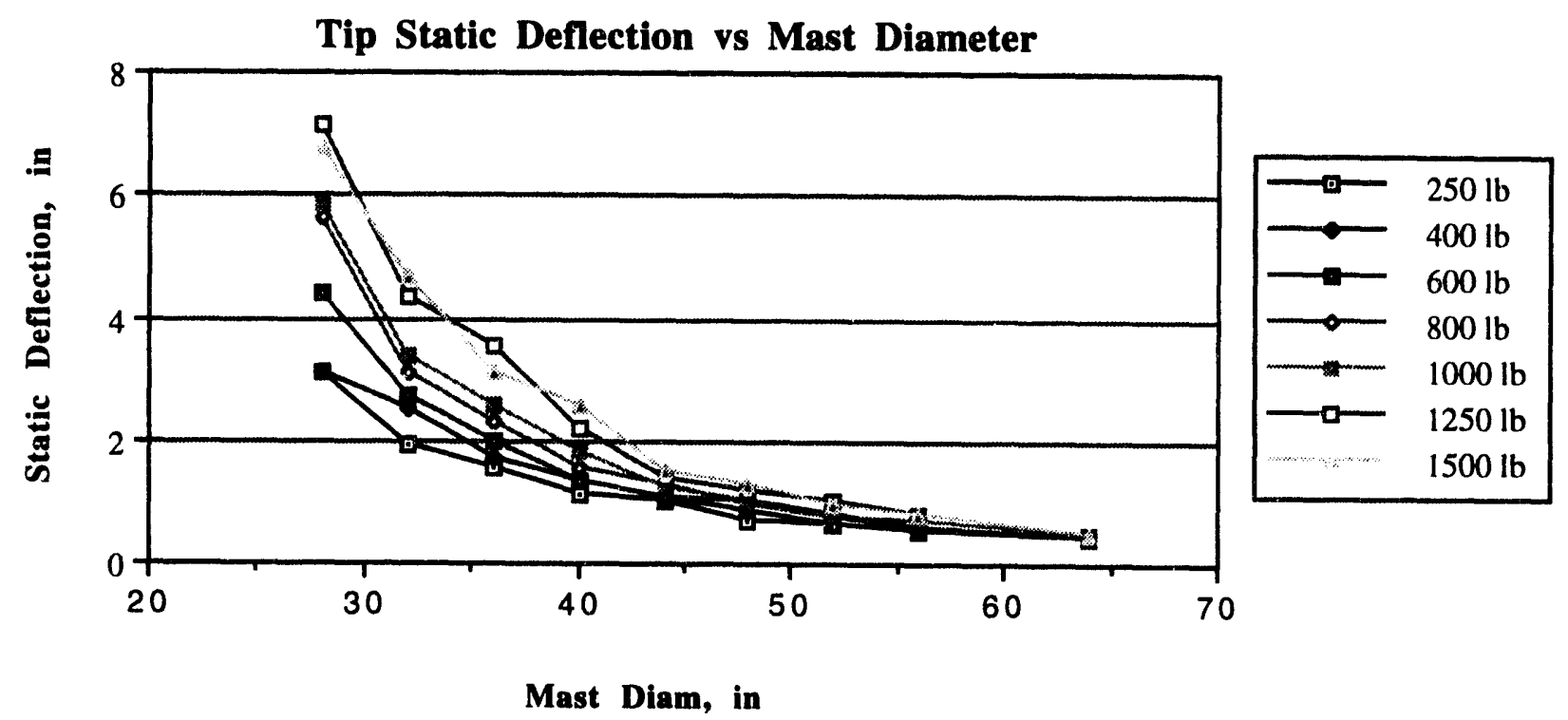

Figure 3 - Relationship between Mast Diameter and Tip Static Deflection 


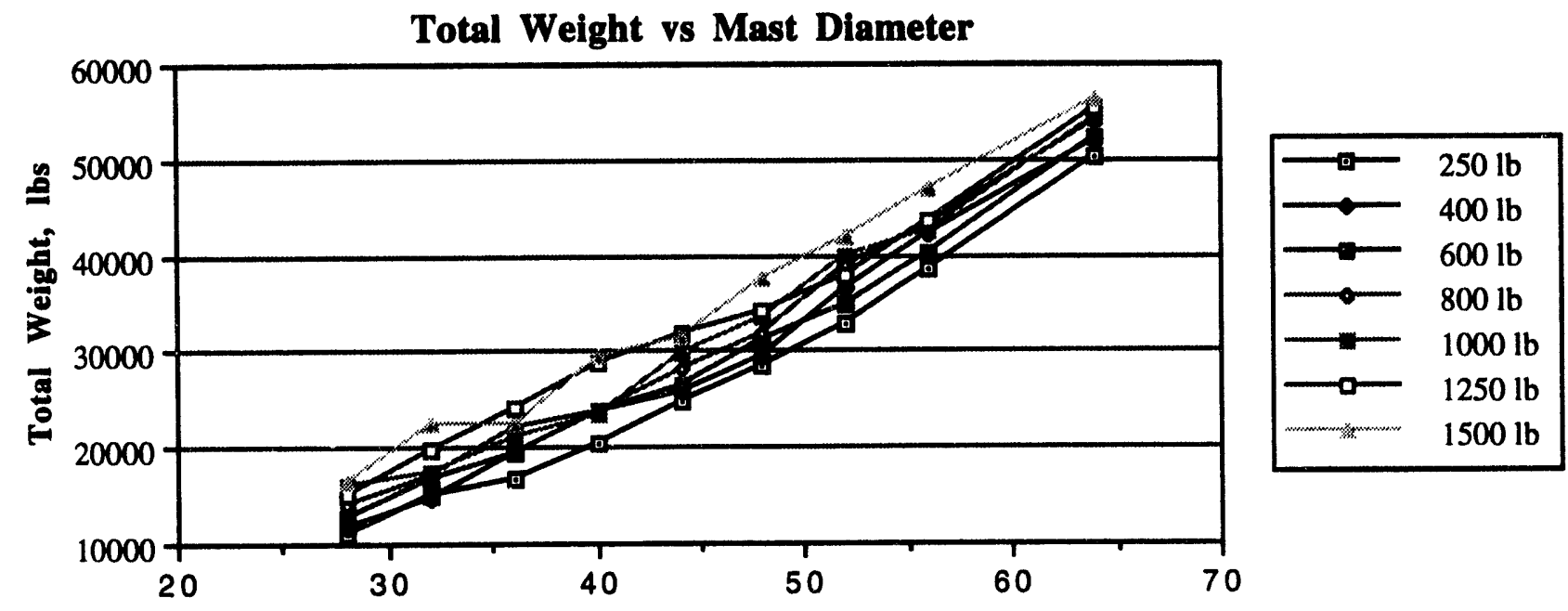

Mast Diam, in

Figure 4 - Relationship between Mast Diameter and Total System Weight

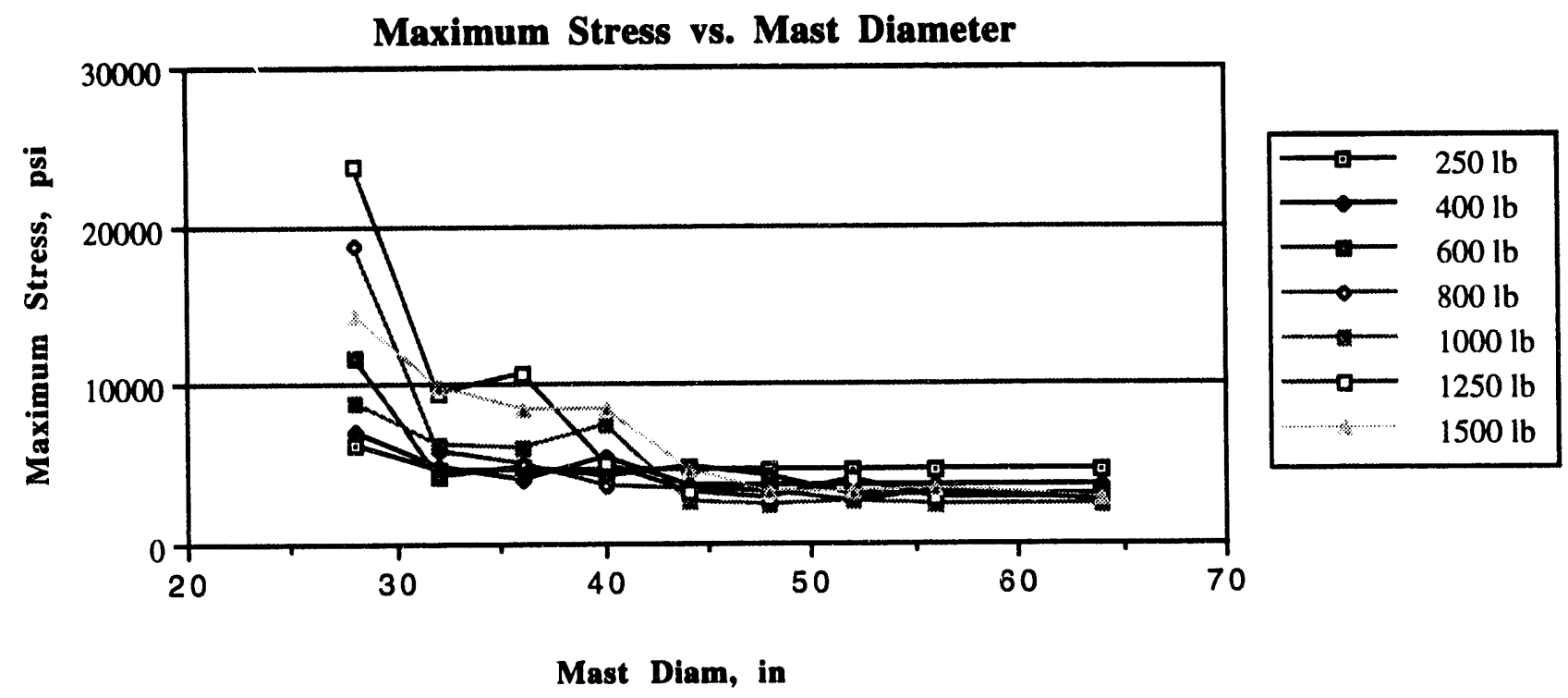

Figure 5 - Relationship between Mast Diameter and Maximum Stress 


\begin{tabular}{|c|c|}
\hline Mode & Frequency (Hz) \\
\hline 1 & 2.73157356 \\
\hline 2 & 2.86828622 \\
\hline 3 & $5: 77832638$ \\
\hline 4 & 6.05408342 \\
\hline 5 & 18.3534854 \\
\hline 6 & 18.7891548 \\
\hline 7 & 39.0917008 \\
\hline 8 & 40.7180039 \\
\hline 9 & 76.9509765 \\
\hline 10 & 81.8466639 \\
\hline 11 & 88.0173375 \\
\hline 12 & 145.970223 \\
\hline 13 & 310.261464 \\
\hline 14 & 507.184577 \\
\hline 15 & 654.493859 \\
\hline
\end{tabular}

Table 1 - Typical System Natural Frequencies (Optimized solution with $1000 \mathrm{lb}$ payload and 48-in. mast diameter) 
PNL-9439

UC-510

\section{DISTRIBUTION}

No. of

Copies

\section{OFFSITE}

12 DOE/Office of Scientific and

Technical Information

Dr. Linton Yarbrough

DOE/Office of Technology

Development

U.S. DOE

Washington, DC 20545

Ray Harrigan

Sandia National Laboratory

Intelligen $\_$Systems \&

Robotics Section

PO Box 5800

Albuquerque, NM 87185

Dan Horchel

Sandia National Laboratory

Intelligent Systems \&

Robotics Section

PO Box 5800

Albuquerque, NM 87185

Scott Babcock

Oak Ridge National Laboratory

PO Box 2008

Building 7601

Oak Ridge, TN 37830
No. of

Copies

Barry Burkes

Oak Ridge National Laboratory

PO Box 2008

Building 7601

Oak Ridge, TN 37830

Bill Hamel

Oak Ridge National Laboratory

PO Box 2008

Building 7601

Oak Ridge, TN 37830

\section{ONSITE}

DOE Richland Operations Office

DE Trader, K8-50

Westinghouse Hanford Company

PW Gibbons, S4-58

LB McDaniel, S6-12

EJ Shen, S4-58

21 Pacific Northwest Laboratory

DM Boyd, K5-10

DW Bennett, K5-17

JW Brothers, K5-22

MS Evans, K5-22

RS Stoughton, K5-22 (10)

SC Slate, K1-19

Publishing Coordination

Technical Report Files (5)

Distr.1 

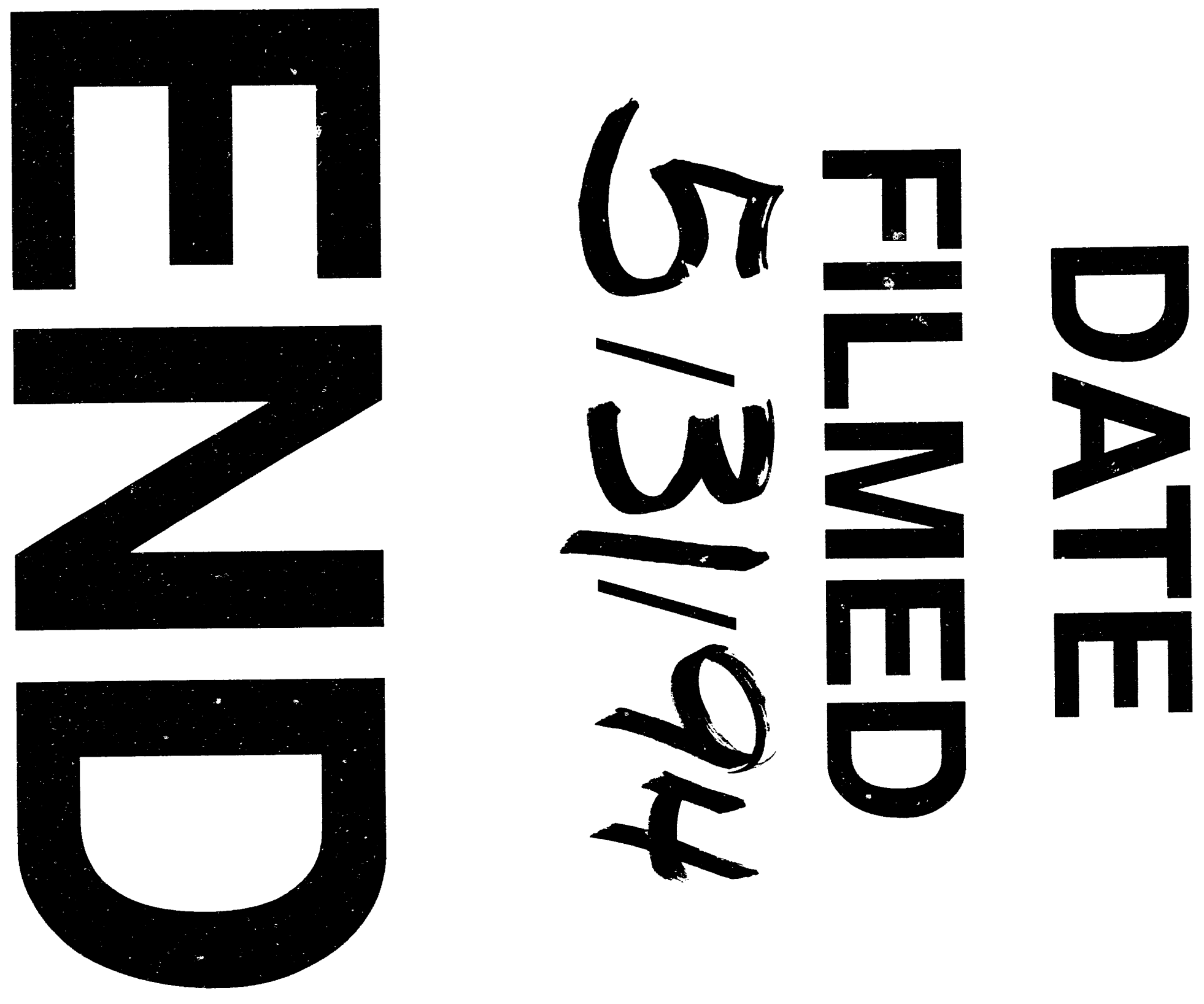
